Submitted to Int. Conf. on Industrial Applications of Synchrotron Radiation Hyogo Prefecture, Japan Nov. 7, 1995

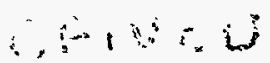

FEB 08 19S0

OSTI

\title{
SYNCHROTRON RADIATION APPLICATIONS IN MEDICAL RESEARCH
}

\author{
W. Thomlinson \\ National Synchrotron Light Source \\ Brookhaven National Laboratory \\ Upton, NY 11973
}

Over the past two decades there has been a phenomenal growth in the number of dedicated synchrotron radiation facilities and a corresponding growth in the number of applications in. both basic and applied sciences. From the very beginning it was recognized that the synchrotron provides an ideal $\mathrm{x}$-ray source for many applications in the biomedical sciences. The high flux and brightness, tunable beams, time structure and polarization were important parameters in the growth of structural biology and molecular dynamics. Today protein crystallography is one of the fastest growing fields being developed for the second and third generation sources.

Beginning in the late 1970's, it was recognized that the synchrotron radiation beams could also be applied to diverse in-vivo research and clinical problems such as coronary and cerebral imaging, mammography, and radiotherapy. There is thus a dual aspect to the field of medical applications of synchrotron radiation. First there are the important in-vitro programs such as structural biology and designer drug design, flourescence analysis of trace elements, $\mathrm{x}$-ray microscopy, and radiation cell biology. Second there are the programs that are ultimately targeted at in-vivo-applications. This paper will discuss the advantages of the synchrotron radiation to the in-vivo basic and applied programs of coronary angiography, multiple energy computed tomography, mammography and radiation therapy. The present status of the programs at laboratories around the world will be reviewed and some future projections for these applications will be made.

\section{DISCLAIMER}

This report was prepared as an account of work sponsored by an agency of the United States Government. Neither the United States Government nor any agency thereof, nor any of their employees, makes any warranty, express or implied, or assumes any legal liability or responsibility for the accuracy, completeness, or usefulness of any information, apparatus, product, or process disclosed, or represents that its use would not infringe privately owned rights. Reference herein to any specific commercial product, process, or service by trade name, trademark, manufacturer, or otherwise does not necessarily constitute or imply its endorsement, recommendation, or favoring by the United States Government or any agency thereof. The views and opinions of authors expressed herein do not necessarily state or reflect those of the United States Government or any agency thereof. 



\section{INTRODUCTION}

The field of medical applications of ionizing radiation, like all of $\mathrm{x}$-ray physics, got its start on November 8, 1895 when Wilhelm Konrad Roentgen discovered x-rays [1]. Within weeks, laboratories throughout the world were studying the applications of the new wonder rays. The news of the discovery almost immediately crossed the Atlantic Ocean and the United States' laboratories became no less involved than their European counterparts. The medical profession reacted swiftly to the possibility of using the rays as a diagnostic tool. Today, a major segment of health care involves the use of both internal and external sources of $x$-rays for imaging and radiotherapy.

In some ways, the synchrotron $\mathrm{X}$-ray community finds itself in a situation similar to that of 100 years ago. A new, powerful tool has been developed, it is in use around the world, and scientists from all disciplines, including medicine, are eager to develop applications for it. There has been a phenomenal growth in the number of synchrotron facilities and the energy range has extended from the infra-red to hard $x$-rays. The utilization of synchrotron radiation facilities for medical purposes is just one of the latest in a long, successful line of advances in technology.

In order to understand the role that the synchrotron will have in the overall health care field it is necessary to be aware of competing technologies that are presently utilized as well as their potential. In particular, magnetic resonance, digital angiography and utrasound are important competing modalities. Table 1 presents the most commonly used medical imaging and therapeutic modalities which utilize ionizing radiation, as well as two which are commonly used now which do not. They are shown for completeness since they indeed compete with $\mathrm{x}$-ray based imaging, and they present less risk to the patients. The discussions in this paper will be limited to those areas where the fields of medicine and synchrotron radiation science have joined to create new tools for medical research, diagnosis, and treatment. The unique properties of synchrotron radiation have given rise to important in-vitro and in-vivo research programs. Some general discussion of both will follow, however the detailed discussions will concentrate on those applications which will involve in-vivo research or which are directly associated with such programs.

\section{UNIQUE PROPERTIES OF SYNCHROTRON RADIATION}

The advent of dedicated synchrotron facilities made possible the long term planning for the utilization of the $\mathrm{x}$-ray and ultra-violet beams in medical research programs. The overriding features of the synchrotron beams which make them applicable to medical research are their extremly high intensity and broad-band energy spectrum. As an example, Fig. 1 shows the $\mathrm{x}$-ray spectrum from the X17 superconducting wiggler beamport at the National Synchrotron Light Source (NSLS) [2] compared with a high power conventional tube source. Several orders of magnitude separate the two spectra and the smooth, continuous spectrum from the synchrotron contrasts with the sharply peaked characteristic emission peaks from the tube. The advantages of the synchrotron arise mainly from these two features and are summarized in Table 2. Basically, the high intensity and tunability allow monochromatic beams to be generated at virtually any energy. The standard problem of beam hardening in both medical imaging and therapy is eliminated by the monochromatic beams since the energy spectrum does not change with passage through tissue, only the intensity changes. The tunable spectrum allows enhancement of images and therapeutic dose by selection of the most effective energy for a given procedure. Examples 
will be given later of the use of K-edge absorption enhancement for imaging and radiotherapy. Benefits to the patients, important considerations in human applications, come from more effective dose delivery in therapeutic modalities and less dose with greater image quality in imaging procedures.

Along with the high intensity and tunability, there are several other advantageous properties of the synchrotron which are sometimes utilized in the research programs. The beams are very highly collimated in the vertical direction and are thus ideal for basic research programs such as protein crystallography and small angle scattering. This geometry is also perfect for the cerebral multiple energy computed tomography program to be discussed later. The radiation is emitted in very short pulses, with a well defined time between pulses. Some research programs have started to use this feature in doing real-time molecular dynamics and structural studies. The radiation is also plane polarized in the plane of the storage rings where the radiation is produced. This feature is exploited by researchers studying the helicity of DNA, for example, with a technique known as circular dichroism.

The advantages of the synchrotrons and their powerful beams come with some distinct disadvantages for medical applications. These are noted in Table 2 and are important for both technical and sociological reasons. The planar beam geometry, mentioned above as an advantage in some programs, is a distinct disadvantage when one tries to create a large two-dimensional image. That is one of the problems in the human coronary angiography projects to be discussed later. However, in the basic research areas, there are few such disadvantages. The real problem comes when considering the application of synchrotrons to clinical diagnostic programs for humans or even large scale research programs involving human subjects. At present, and in the foreseeable future, there is little access to the synchrotron beams for medical purposes, due both to lack of development of such programs and the very high cost of both facilities and research beamlines. Assuming that technical matters can be solved, it will be imperative to develop compact, high-energy spectrum sources which will be cost effective for hospitals, research centers, or medical centers [3]. Without such development, the medical applications will be limited to a few well defined research programs.

The short term future is clearly along the lines of basic research in which drug development may take place, new radiotherapy techniques may be developed and tested, and advanced imaging systems may become successful. These will all certainly happen on today's first and second generation sources and tomorrow's third generation sources. Whether or not any programs reach the level of clinical diagnostic or treatment centers will depend on the success of the present research programs, the acceptance of these technologies by the medical community, and the development of new compact sources.

\section{SYNCHROTRON RADIATION APPLIED TO MEDICAL IMAGING}

Synchrotrons have been have been used in virtually all areas of medicine which use ionizing radiation. The research has not been confined to any one facility, but is being carried out throughout the world [4]. A summary of most of the current research areas which involve synchrotrons is given in Table 3. The applications are directed at many of the most difficult and important medical problems facing the human race. The research, as will be seen in detail later, is directed at brain and breast cancer imaging and therapy, development of new drugs, evaluation of cellular function, and coronary artery imaging in a manner which is safer for the patient than conventional means. This section will describe the major applications to both in-vitro and in-vivo medical imaging. 


\section{A. MICRO-IMAGING}

Some programs such as structural biology[5] and EXAFS (Extended X-ray Absorption Fine Structure) [6] will only be in-vitro medical research due to the basic research nature of the subject matter. Entire books and conferences are dedicated to these basic science applications of synchrotron radiation so they will not be treated any further in this paper. The development of very high brightness synchrotron radiation sources has led to major advances in soft $\mathrm{x}$-ray microscopy (SXRM). The microscopes require the coherent flux and high intensity available from these sources. The first of the two types of microscope is the SXRM which uses X-rays in the wavelength range known as the water window. Between the carbon and oxygen K-edges (2.5 - 4 $\mathrm{nm}$ ) water is relatively transparent. Thus, wet biological specimens can be imaged with high contrast, especially in systems employing the technique of $\mathrm{K}$-edge digital subtraction imaging. There are a number of soft $\mathrm{x}$-ray microscopes operating around the world. The present generation of microscopes has been constructed on undulator lines to take advantage of the extremely high brightness of the sources. Some of the instruments currently being operated are at Daresbury [7], BESSY [8], the Photon Factory [9], and the NSLS [10]. It may eventually be possible to image wet biological samples in three dimensions.

In order to image dense, high $Z$ materials or to study trace elements of high $Z$ materials in. a matrix such as bone, it is necessary to turn to the $x$-ray microscope (XRM). In the present context that means one which operates on a hard $x$-ray line at energies greater than about $3 \mathrm{keV}$. An example of such a beamline is one built at the NSLS [11]. Images can be produced by measurement of fluorescent $\mathrm{x}$-rays or of the attenuation of the incident beam by the specimen.

Because of the higher energies of this instrument, computed microtomography can be used for nondestructive images through the specimen in either fluorescence emission or absorption mode. Studies of the distribution of trace levels of therapeutic gallium in bone [12], tendonitis [13] and osteoneogenesis [14] illustrate the applications of the XRM and microtomography to biomedical problems.

The research projects to be highlighted in this paper have potential either for direct human subject involvement with the synchrotron $\mathrm{x}$-ray beams (coronary angiography, mammography, computed tomography, and radiotherapy) or indirect involvement through the development of radiation dose enhancement drugs (photon activation therapy). Only the coronary angiography programs at the NSLS and HASYLAB presently involve in-vivo human studies although human studies are expected in Japan in 1996 and at the ESRF in 1997. Early radiotherapy work at the NSLS and ESRF has proceeded to the animal model stage. It is expected that within a few years, additional radiotherapy, mammography, angiography, and cerebral computed tomography programs will reach the in-vivo human studies level.

\section{B. MULTIPLE-ENERGY COMPUTED TOMOGRAPHY}

Monochromatic synchrotron $x$-rays have two distinct advantages over the wide-energy band bremsstrahlung radiation obtained from $x$-ray tubes for radiology in general and for computed tomography (CT) in particular. The monochromatic x-rays do not "beam harden", an effect in which the low energy end of the photon spectrum attenuates more than the high energy end. The average energy shifts to higher energy as a function of penetration into the body. This is particularly troublesome for image reconstruction of CT images. Second, the tunability of the spectrum allows both dual-photon absorptiometry (DPA) and K-edge subtraction (KES) 
imaging. A system called Multiple Energy Computed Tomography (MECT) has been developed at Brookhaven National Laboratory which utilizes synchrotron radiation beams for DPA and KES of the human cerebrum [15-18]. The system has been developed at the X17 beamport of the NSLS [2]. A new program for MECT, similar to the one at the NSLS, is being developed at the ESRF and is expected to begin experiments in 1996 [19]. One Japanese program is studying high contrast CT imaging with synchrotron radiation [20-22]. In addition to these computed tomography programs in which the patient will be rotated in the synchrotron beam, a fluorescent scanning tomography system is being developed at the Photon Factory [23]. That system will investigate nonradioactive trace materials in living systems using a system which scans the sample in two orthogonal directions while detecting the fluorescent radiation excited by the synchrotron radiation. A recent development at the Photon Factory has been a system for studying phasecontrast $\mathrm{X}$-ray computed tomography for biological specimens and organic materials [24].

DPA is an imaging method in which the attenuation of $x$-rays at two greatly different energies (e.g. 40 and $100 \mathrm{keV}$ ) is measured to obtain two different images of the subject. One mainly represents the concentrations of low $Z$ elements and the other mainly the intermediate $Z$ elements. The DPA image of the low $Z$ element group will emphasize concentrations of $H, C, N$, $\mathrm{O}$, and $\mathrm{Na}$ while that of the intermediate $\mathrm{Z}$ group will emphasize $\mathrm{P}, \mathrm{S}, \mathrm{Cl}, \mathrm{K}, \mathrm{Ca}$, and $\mathrm{Fe}$. In particular, the second group includes the neurologically important elements $\mathrm{K}$ and $\mathrm{Ca}$. Abnormal brain-tissue concentrations of these elements may reflect disorders such as ischemia and incipient. infarction. KES utilizes the large rise in the photoelectric absorption cross section at the K-edge of elements. The introduction of a contrast agent and imaging with two energies on either side of the $\mathrm{K}$-edge can give high contrast images of the vasculature in the brain.

The synchrotron geometry is ideal for doing CT of the brain, since beams are naturally collimated in the vertical direction and are fan shaped in the horizontal plane. In addition, the highly collimated beams allow the detector to be placed far behind the patient, thus reducing the problem of subject to detector scatter. The CT configuration is that of a fixed, horizontal fan beam and a subject seated in a rotating chair. Fig. 2 shows a view of the experimental geometry looking down from above the patient. MECT's potential is based on the beam's narrow energy bandwidth of about $0.2 \%$ which eliminates beam-hardening artifacts and allows the efficient use of DPA and KES. The KES studies will image the brain, large blood vessels of the head and neck, and arteriovenous malformations. DPA will obtain images that map the low $Z$ and intermediate $Z$ elements. The imaging studies take place in the SMERF facility, the synchrotron medical research facility now in operation on the $\mathrm{X} 17$ beamline for the coronary angiography project [25].

Thus far, the NSLS facility has been used in the MECT program to image phantoms and live rabbits. The present field of view is $14 \mathrm{~cm}$ in an energy range of $24-52 \mathrm{keV}$. In the clinical stage, the view will be $19 \mathrm{~cm}$ in an energy range of $33-100 \mathrm{keV}$. A two crystal bent Laue system is being developed for the clinical stage. The final system will be composed of two such monochromators to cover the two energy ranges for DPA. The energy-switching time will be 2 seconds. The detector being developed for this system is a modular, seamless linear-array device made of $\mathrm{CdWO}_{4}$ scintillators coupled to PIN diodes [18]. Iodine K-edge subtraction and single energy prototype experiments have been carried out, with human studies scheduled to start in 1997. 


\section{C. MAMMOGRAPHY}

Screening mammography has proven to be an effective procedure in identifying early breast cancer. The cancers found by mammography tend to be smaller and less advanced than those found by physical examination, resulting in better survival rates. Mammographic technology has dramatically improved in the last two decades, but approximately $10 \%$ of clinically obvious breast cancers are not visible with mammography. Further improvement in detection is expected with the advent of digital mammography which utilizes better source geometry and improved detector systems. It has been suggested very frequently that perhaps the use of the synchrotron source with its inherently highly collimated, tunable radiation could increase the signal to noise and increase the contrast resolution in the images, possibly at lower dose to the patient.

Several experimenters have used the synchrotron in preliminary experiments aimed at understanding the role of synchrotron radiation in the mammography field. Carroll, et al [26], have shown that there are significant differences in attenuation between normal and cancerous tissues for monoenergetic $x$-rays in the range of 14 to $18 \mathrm{keV}$. Boone and Seibert [27] did a computer simulation comparing monoenergetic $\mathrm{x}$-rays to polyenergetic $\mathrm{x}$-rays with regard to imaging, concluding that the monoenergetic sources should have a 40 to $200 \%$ improvement in contrast. Burattini, et al $[28,29]$, recently reported their work using synchrotron radiation and conclude that the monochromatic images have higher contrast, better resolution, and similar or less radiation dose. Recent calculations have also shown that there is improved contrast and signal-to-noise ratio in monoenergetic images which lead to improved resolution of microcalcifications [30]. In order to advance the state-of-the-art in synchrotron mammography, a dedicated.beamline is being constructed at the ELETTRA facility in Trieste, Italy. The beamline will be used for advanced digital detector development and general advancement of the mammography technology [31].

Over the past year, a set of preliminary experiments has been done by Johnston, et al at the NSLS, using monoenergetic $x$-rays to explore, in detail, the potential of monoenergetic photons for mammographic imaging [32]. The experiments have shown that superior image contrast can be obtained relative to the conventional film-screen techniques. As an example of the results, Fig. 3 shows a comparison between contrast measured in a contrast detail phantom at $18 \mathrm{keV}$ and the same data obtained on a conventional system. Images of various mammographic phantoms and real tissue were carried out in the energy range 16 to $24 \mathrm{keV}$.

In these early experiments, it was clear that improved contrast at equivalent or less dose is obtained. Scoring of the phantom images according to American College of Radiology criteria shows improvement over the conventional systems, with similar or less mean glandular dose. The future plans include optimization of the monochromator, sample orientation and translation system, and detector. The early work at the NSLS utilized available image plate and conventional mammographic film detectors. It is planned to study digital detector systems, scanning monochromators and imaging technology incorporating an analyzer crystal to obtain scatter free images. The elimination of scatter is expected to produce images with higher contrast than conventional imaging systems. A preliminary experiment has been reported by Chapman, et al. at the NSLS [33]. One research group has recently reported on the development of phase contrast techniques for biomedical imaging [24]. Direct comparisons between the synchrotron system and conventional systems will continue to be made using tissue samples obtained from patient specimens containing different types of cancers (masses, calcifications, and architectural 
distortions). In the long term, it may be possible to advance the program to human studies in the medical research facility at the NSLS.

\section{D. CORONARY ANGIOGRAPHY}

Certainly the most advanced of the applied medical research programs at synchrotron facilities are those doing human coronary angiography. The field traces its origins back to the proposal that the intensity of the synchrotron $x$-ray beams would be high enough to allow imaging of the coronary arteries following venous injection of an iodine containing contrast agent [34].

The reason such a procedure is desirable is that the standard arterial catheterization method (contrast agent injected directly into the coronary arteries) presents significant enough risks that it is generally not used for clinical screening or research. Certainly the images obtained are excellent and necessary for acute trauma. However, for coronary artery disease research to use humans subjects for imaging, the venous technique is highly desireable. Using conventional sources, this method proved to be a failure due to motion artifacts in the images and not enough flux to allow sufficient contrast between the small arteries containing highly diluted contrast agent overlying the large coronary structures. Even applying digital subtraction imaging at the iodine $\mathrm{K}$-absorption edge proved a failure with conventional sources. In recent years magnetic resonance imaging has made progress in imaging the coronary arterial tree [35]. However, the images take a very long time to acquire and are not yet capable of showing anything except the very slowly moving proximal portions of any of the coronary arteries.

Since the first proposal, several groups around the world have taken various approaches to using the synchrotron for doing coronary angiography. The various projects have been developing single-energy and dual-energy imaging, one and two dimensional imaging systems, and venous and arterial injection modalities. Both differences in the $x$-ray optics and the types of detectors appear among the experimental groups depending upon the needs of the technology. The pioneering work in angiography in Russia at the Institute of Nuclear Physics [36,37] and the programs at the NSLS [38-41] and HASYLAB [42-44], as well as the planned work at the ESRF $[19,45]$, move the patient through a stationary one-dimensional fan beam. Fig. 4 is a schematic representation of the system at the NSLS. The two-dimensional image is thus acquired by combining many horizontal one-dimensional lines to create the necessary two-dimensional image. Motional artifacts are avoided by taking each line of data in a time short compared with the motion of the heart.

In contrast to the line-scan mode, the programs in Japan at the Photon Factory $[46,47]$ are working toward taking very rapid, two-dimensional exposures. They have developed two distinct optical configurations and have been testing the ideas with animal studies. Fig. 5 shows an example of the system developed by Takeda, et al [48]. They are attempting to use a single energy above the k-edge of iodine with transvenous injection. Human studies are expected to start in 1996 [49]. In another program, micro-angiography is being applied to the study of microarteries in the heart [50]. Finally, the use of fast filter assemblies to switch the beam energy above and below the iodine k-edge has also been studied with some success on animals [51].

In Germany at HASYLAB the researchers have developed a technology much like that first described by the Stanford group in which the image is built up out of a large number of line images. In this geometry the patient must be translated through the beam. This type of image gives very good results, but takes a significant fraction of a second for a full scan. Although motional artifacts are virtually non-existent, the long time per scan means that phasing the images 
to the electro cardiogram is difficult. In addition, one of the major goals of the transvenous imaging has been to advance to where the contrast agent can be injected into a peripheral vein [44]. The German group headed by Dr. W.-R. Dix has made major advances in each of these areas of the technology having imaged 76 patients to date. Fig. 6 shows an image taken at HASYLAB following peripheral injection into the brachial vein. It is clearly of equal quality to the accompanying image, Fig. 7, taken at the NSLS with injection into the superior vena cava.

The concept of synchrotron based coronary angiography was first developed at Stanford University and the early human studies were done at the Stanford Synchrotron Radiation Laboratory $[38,39]$. In 1989 the project moved to the NSLS where the hardware was installed in the SMERF medical research facility $[25,40,41]$. The patient moves vertically through the cross-over point of two beams, one above the iodine K-edge and the other below the edge as shown earlier in Fig. 4. Each line of data is taken in between 1 and 4 milliseconds with a complete scan taken with 256 lines. The HASYLAB system can take data at a rate of about 1 msec, similar to the design at the ESRF and the upgraded beamline at the NSLS. Spatial resolution is presently between 0.25 and $0.5 \mathrm{~mm}$. Excellent images of the right coronary artery and of the left anterior descending coronary artery have been obtained at the NSLS and HASYLAB. At both laboratories, the circumflex artery has been more difficult to image, but can be seen in particular patients with the proper angulation for the image.

Much of the recent work at HASYLAB and the NSLS has centered on determining the optimal projection angle for studying each artery. These studies, in parallel with gating of the images from the ECG and peripheral injection, have advanced the technology to a point where definitive medical research can begin. Continued progress in the development of digital detectors, low noise imaging systems, and advanced image processing algorithms will lead to even better images with true quantification of disease a real possibility $[52,53]$. One very important program will be the studies at the ESRF in both angiography and computed tomography aimed at developing higher $\mathrm{Z}$ contrast agents for imaging. It has been shown theoretically that iodine is not the best choice with respect contrast maximization and dose minimization. In fact, gadolinium would be ideal if it could be used in sufficient concentrations [54].

\section{E. BRONCHOGRAPHY}

Recently, Rubenstein, et al have described a medical imaging procedure using xenon as a contrast agent for $\mathrm{K}$-edge dichromography of the respiratory air passages $[55,56]$. The process could provide the opportunity to image anatomic structures and pathologic processes that cannot be visualized by conventional $\mathrm{x}$-ray based imaging methods. For example, detection of lung cancer, the leading cause of cancer related deaths in the US, is an important application. At present, standard $\mathrm{x}$-ray procedures cannot detect tumors less than $1 \mathrm{~cm}$ in diameter. It has been calculated that synchrotron imaging with xenon could detect significantly smaller, earlier tumors leading to enhanced five-year survival. There have been suggestions in the past of using xenon in $\mathrm{CT}$ measurements of cerebral blood flow and pulmonary function $[57,58]$, and very recently MRI has been used with helium (and suggested for use with xenon) to image the lungs [59]. For the synchrotron bronchography, the airway structures are imaged after inhalation of a gas mixture containing stable xenon. The amount of inhaled gas is limited to the anatomic dead space volume of the upper and lower air passages. The subjects hold their breath for several seconds while the images are recorded using the dual-energy imaging system developed at SSRL and the NSLS for coronary angiography. Initial studies on human volunteers have been carried out at the NSLS in a recent experiment [60]. For these studies, the $\mathrm{X} 17$ beamline was aligned to bracket the xenon $\mathrm{K}$ - 
edge at $34.56 \mathrm{keV}$. The procedure was identical to the angiography imaging except that the contrast agent was inhaled instead of being injected. In these preliminary experiments the trachea and bifurcation of the bronchus could be seen, even with only about $10 \%$ xenon in the airway. The results were very promising and future work has been planned.

\section{RADIOTHERAPY}

Radiotherapy is that process whereby a large dose of ionizing radiation in the form of gamma-rays, $x$-rays, or particle beams is targeted onto a tumor in order to kill the cells. The dose can be delivered by external beams created by $x$-ray machines or from the decay of radioactive sources such as Co-60. The dose can also be delivered by use of radioisotopes such as I-125 or Cs-137 which are delivered into the body to the tumor site or encapsulated and inserted into the region of the tumor. One of the main problems associated with all of these forms of therapy, although sometimes effective in killing the malignant cells, is the attendant high radiation dose to the normal tissue which is in the region of the tumor or, in the case of external beam therapy, between the external body surfaces and the deeply buried tumor.

There are two ways being studied with synchrotron radiation to enhance the effectiveness of radiotherapy. The first is to increase the sensitivity of the target tumor cells to the radiation, leading to increased death of the cells while sparing normal cells. The tunability and. monochromaticity of the synchrotron radiation makes this approach possible. An example of an application in the field of radiobiology is Photon Activation Therapy (PAT) [61]. The second approach, first suggested by Larsson [62], is to use the inherent collimation of the synchrotron beams to create a beam geometry which optimizes dose delivery to the tumor site but also effectively spares intervening normal tissue. An example of this application will be discussed under the heading of Microbeam Radiation Therapy (MRT) [63].

\section{A. PHOTON-ACTIVATION THERAPY}

The study of radiobiology using synchrotron radiation has had a long. history. However, most of the early work centered around the effects of ultra-violet radiation on cells [64]. With the development of higher energy machines, the $x$-ray range became accessible and biological effects of inner shell photoabsorption began [65]. Much of the work has centered around the study of phosphorus since it is located at the strategic position in the DNA molecule. However, in order to apply any radiation to in-vivo therapy, the energy range must be much higher for either implanted sources or external beams. The study of heavier elements such as iodine and indium has thus proceeded, with much of the emphasis on determining the means of incorporating the target atoms in the cell and the efficacy of the potential treatment. An example of a potential application using stable iodine will be given. However, there are exciting new experiments being conducted and planned which will utilize indium as the target element.

Photon Activation Therapy (PAT) is a system being investigated as a therapeutic modality for the treatment of malignancies, particularly the highly lethal and malignant brain tumor, glioblastoma multiforme. The PAT process, first suggested by Fairchild [61], involves the incorporation of a target atom in the immediate vicinity of a cell's critical site (DNA), followed by the activation of this atom with photons of energies suitable for the induction of the photoelectric effect and its concomitant Auger cascades. The Auger electrons impart significant damage at the critical site. In 1977 it was postulated [66] that through the use of stable halogenated pyrimidines incorporated in cellular DNA, followed by their activation with 
monochromatic photons above the K-absorption edge of the halogen, the photoelectric absorption would lead to the release of Auger electrons, contributing additional ionization within the DNA. Radiation would then preferentially damage the malignant cells since they have incorporated the halogen.

Several investigators have attempted to demonstrate the increased effectiveness of $x$-rays attributable to the Auger effect using BrdUrd (5-bromo-2'-deoxyuridine) as an analog of thymidine in the cellular DNA $[67,68,69]$. All of the results failed to show any substantial enhanced sensitivity due to Auger processes. Work at the NSLS has confirmed the absence of measureable effects with BrdUrd using Chinese hamster V-79 cells [70].

However, as an example of the effectiveness of using a higher $Z$ target atom, some work has been reported in which iodine has been incorporated into the DNA of V-79 Chinese hamster cells [71]. The iodine was in the form of stable $I-127$ in the halogenated pyrimidine 5-iodo-2'-deoxyuridine (IdUrd) and was incorporated into the cellular DNA during cell replication as an analog of the natural base thymidine. The target atom was the iodine and the experiments used monochromatic photons above the $\mathrm{K}$ absorption edge at $33.17 \mathrm{keV}$. Although IdUrd is a known cell sensitizing agent, those experiments were designed to separate out the effects due to the Auger effect. Monochromatic photons above $(33.4 \mathrm{keV})$ and below $(32.9 \mathrm{keV})$ the iodine $\mathrm{K}$-edge were used to determine if any additional biological damage would accrue from the Auger cascades. The $33.4 \mathrm{keV}$ photons were found to be a factor of 1.4 times more effective in increasing the severity of damage to the iodinated cells than were the $32.9 \mathrm{keV}$ photons. In this experiment there was a $16.3 \%$ replacement of thymidine by the IdUrd. The total therapeutic gain (relative to the non-iodinated controls) was a factor of 3.1. PAT has been described as a potential clinical modality for the treatment of malignant brain tumors [72]. Samarium-145, which emits $40 \mathrm{keV}$ photons, has been identified as a radioisotope which is nearly ideal for PAT with iodine. Implantation of Sm-145 brachytherapy sources can be used for delivering radiation locally. The halogen in this experiment was incorporated into the DNA. In more recent work, however, the target atoms have been transported intracellularly by a porphyrin (InBOPP) [73] and oxine [74] for indium or Hoechst 33258 for iodine [75]. The exact location of the target atoms in these latter experiments has not been determined and whether or not there will be a substantial theraputic gain has not been definitively established.

\section{B. MICROBEAM RADIATION THERAPY}

One of the most effective means of increasing the dose to the tumor and sparing intervening normal tissue is to use stereotactic radiosurgery [76]. In that procedure one or more highly collimated radiation beams are directed at the tumor from varying directions. The crossing point of the beams is at the target tumor, thereby delivering a dose equal to the sum of all the beams to the target and delivering a fraction to all other tissue.

The monochromatic synchrotron radiation beams can be very highly collimated in either planar or cylindrical beam geometries and can be either focusing or non-focusing. With the development of high energy sources it is now possible to have beams with energies in the range of $50 \mathrm{keV}$ and above. These are excellent for targeting tumors deep in the brain. The geometry is ideal for stereotactic radiosurgery and the monochromatic beams will not beam harden. Hence, the radiation dose to the patient will be efficiently delivered [62]. Microbeam Radiation Therapy (MRT) is a concept developed by Slatkin and co-workers in which a lesion would be irradiated in a stereotactic fashion using bundles of multiple, parallel, microscopically narrow beams of $\mathrm{x}$-rays $[63,77,78]$. The energy range required is $50-150 \mathrm{keV}$. The microbeams would each be planes 
several millimeters high and 25-100 microns wide. The beams in each bundle would be separated by center to center distances of 50-200 microns. The detailed spacing and beam widths will be determined by experimentation based on the results of Monte Carlo calculations. The central hypothesis is that endothelium in blood vessels destroyed by high absorbed doses within the paths of microbeams would regenerate from endotheliocytes in the minimally irradiated contiguous segments between the microbeams. Tissue necrosis would thus be avoided except in the crossfired target. In the target the tissue sparing effects of the microbeams would be eliminated so that with sufficiently high doses necrosis will occur. The MRT concept has the potential of allowing larger absorbed doses in the target than presently permitted without risk to surrounding tissues [79].

Experiments have been carried out at the NSLS in which it has been shown that MRT is effective in increasing the survival of rats with imminent and inexorable brain tumors [78]. In these experiments the beams were $4 \mathrm{~mm}$ high and 25 micron wide, filtered by $\mathrm{Gd}$ on the X17 beamline at the NSLS. The microplanar beams were separated by 100 micron intervals, center to center. The skin entrance dose rates were about $400 \mathrm{~Gy} / \mathrm{s}$. The present efforts at the NSLS and in Grenoble at the ESRF [80] are continuing both experimentally and theoretically in order to understand the optimal beam parameters and to study the dose distribution theoretically.

One of the most exciting possibilities in the future of synchrotron radiation radiotherapy (and radiosurgery) would be the coupling of synchrotron computed tomography for the mapping of a target area and for treatment planning, with synchrotron microbeam radiation therapy for treatment $[17,81]$. This would combine the high resolution mapping of the CT with the advantages of the synchrotron radiotherapy discussed earlier. Taking this thought to its limit, one can imagine using photon activation therapy in combination with multiple energy computed tomography and the microbeam radiation therapy to effect a very significant total treatment program.

\section{CONCLUSIONS}

The projects discussed in this paper are, for the most part, still in their infancies and no one can predict the direction in which they will develop. Both the basic research and applied medical programs are sure to be advanced at the new facilities coming on line, especially the ESRF and Spring-8. However, success is not guaranteed. There is a lot of competition from advances in conventional imaging with the development of digital angiography, computed tomography, functional magnetic resonance imaging and ultrasound. The synchrotron programs will have to provide significant advantages over these modalities in order to be accepted by the medical profession. Advances in image processing and potentially the development of compact sources $[3,53,82]$ will be required in order to move the synchrotron developed imaging technologies into the clinical world. In any event, it can be expected that the images produced by the synchrotron technologies will establish "gold standards" to be targeted by conventional modalities. A lot more work needs to be done in order to bring synchrotron radiation therapy and surgery to the level of human studies and, subsequently, to clinical applications.

\section{ACKNOWLEDGEMENT}

This work was supported by the US Department of Energy under contract \#DE-AC02$76 \mathrm{CH} 00016$. 


\section{REFERENCES}

[1] O. Glasser, in The Science of Ionizing Radiation, ed., L.E. Etter (Charles C. Thomas, Springfield, 1965) 5 .

[2] W. Thomlinson, D. Chapman, N. Gmür, and N. Lazarz, Nucl. Instr. and Meth. A266 (1988) 226.

[3] H. Wiedemann, M. Baltay, R. Carr, M. Hernandez, and W. Lavender, Nucl. Instr. and Meth. A347 (1994) 515.

[4] W. Thomlinson, Nucl. Instr. and Meth. A319 (1992) 295.

[5] Synchrotron Radiation in Structural Biology, eds., R. Sweet and A.D. Woodhead (Plenum Press, New York, 1989).

[6] Synchrotron Radiation in the Biosciences, eds. B. Chance, et al. (Oxford University Press, New York, NY) 1994.

[7] G.R. Morrison, S. Bridgewater, M.T. Browne, R.E. Burge, R.C. Cave, P.S. Charalambous, G.F. Foster, A.R. Hare, A.G. Michette, D. Morris, T. Taguchi, and P. Duke, Rev. Sci. Instr. 60 (1989) 2464.

[8] G. Schmahl, D. Rudolph, P. Guttman, G. Schneider, J. Thieme, and B. Niemann, Rev. Sci. Instrum. 66 (1995) 1282.

[9] Y. Kagoshima, S. Aoki, M. Kakuchi, M. Sekimoto, H. Maezawa, K. Hyodo, and M. Ando, Rev. Sci. Instr. 60 (1989) 2448.

[10] H. Rarback, C. Buckley, K. Goncz, H. Ade, E. Anderson, D. Attwood, P. Batson, S. Hellman, C.Jacobsen, D. Kern, J. Kirz, S. Lindaas, I. McNulty, M. Oversluizen, M. Rivers, S. Rothman, D. Shu, and E. Tang, Nucl. Instr. Meth. A291 (1990) 54.

[11] K.W. Jones, B.M. Gordon, G. Schidlovsky, P. Spanne, X. Dejun, R.S. Bockman, and A.J. Saubermann, in Microbeam Analysis, eds., J.R. Michael and P. Ingram (San Francisco Press, San Francisco, 1990) 401.

[12] R.S. Bockman, M:A. Repo, R.P. Warrell, Jr., J.G. Pounds, G. Schidlovsky, B.M. Gordon, and K.W. Jones, Proc. Natl. Acad. Sci. USA 87 (1990) 4149.

[13] C. J. Buckley, Rev. Sci. Instrum. 66 (1995) 1318.

[14] K. Engelke, W. Graeff, L. Meiss, M. Hahn, and G. Delling, Invest. Rad. 28 (1993) 341.

[15] F.A. Dilmanian, R.F. Garrett, W.C. Thomlinson, L.E. Berman, L.D. Chapman, N.F. Gmür, N.M. Lazarz, P.N. Luke, H.R. Moulin, T. Oversluizen, D.N. Slatkin, V. Stojanoff, A.C. Thompson, N.D. Volkow, and H.D. Zeman, Physica Medica 6 (1990) 301.

[16] F.A. Dilmanian, R.F. Garrett, W.C. Thomlinson, L.E. Berman, L.D. Chapman, J.B. Hastings, P.N. Luke, T. Oversluizen, D.P. Siddons, D.N. Slatkin, V. Stojanoff, A.C. Thompson, N.D. Volkow, and H.D. Zeman, Nucl. Instr. and Meth. B56/57 (1991) 1208.

[17] F.A. Dilmanian, Am. J. Physiol. Imag. $3 / 4$ (1992) 175.

[18] X.Y. Wu, F.A. Dilmanian, Z. Chen, B. Ren, D.N. Slatkin, D. Chapman, M. Shleifer, F.A. Staicu, and W. Thomlinson, Rev. Sci. Instrum. 66 (1995) 1346.

[19] A.M. Charvet, J.F. LeBas, H. Elleaume, C. Schulze, P. Suortti, and P. Spanne, Proceedings of the International School E. Fermi - CXXVIII Course - Biomedical Applications of Synchrotron Radiation, eds. E. Burattini and A. Balerna (IOS Press, Amsterdam, 1995).

[20] Y. Itai, T. Takeda, T. Akatsuka, T. Maeda, K. Hyodo, A. Uchida, T. Yuasa, M. Kayama, J. Wu, and M. Ando, Rev. Sci. Instrum. 66 (1995) 1385. 
[21] T. Takeda, Y. Itai, K. Hyodo, T. Zeniya, and T. Akatsuka, Med. Imag. Technol. 11 (1994) 621.

[22] K. Umetani, K. Ueda, T. Takeda, M. Akisada, T. Nakajima, and I. Anno, Nucl. Instr. and Meth. A301 (1991) 579.

[23] T. Takeda, T. Maeda, T. Yuasa, T. Akatsuka, T. Ito, K. Kishi, J. Wu, M. Kazama, K. Hyodo, and Y. Itai, Rev. Sci. Instrum. 66 (1995) 1471.

[24] A. Momose, T. Takeda, and Y. Itai, Rev. Sci. Instrum. 66 (1995) 1434.

[25] W. Thomlinson, N. Gmür, D. Chapman, R. Garrett, N. Lazarz, H. Moulin, A.C. Thompson, H.D. Zeman, G.S. Brown, J. Morrison, P. Reiser, V. Padmanabhan, L. Ong, S. Green, J. Giacomini, H. Gordon, and E. Rubenstein, Rev. Sci. Instrum. 63 (1992) 625.

[26] F. Carrol, J. Waters, W. Andrews, R. Price, D. Pickens, R. Wilhott, P. Tompkins, C. Roos, D. Page, G. Reed, A. Veda, R. Bain, P. Wang, and M. Bassinger, Invest. Radiology 29 (1994) 266.

[27] J.M. Boone and J.A. Seibert, Med. Phys. 15 (1988) 713.

[28] E. Burattini, M. Gambaccini, P.L. Indovina, M. Pocek, and G. Simonetti, Radiol. Med. 4 (1992) 181.

[29] E. Burattini, E. Cossu, C. Di Maggio, M. Gambaccini, P. Indovina, M. Maryiani, M. Porek, S. Simeoni, and G. Simonetti, Radiology 125 (1994) 239.

[30] A. Mantykentta-Pramanick and R. Carr, Medical Physics (1995), to be published.

[31] F. Arfelli, G. Barbiellini, G. Cantatore, E. Castelli, P. Cristaudo, L. Dalla Palma, M. Di Michiel, R. Longo, P. Poropat, R. Rosei, M. Sessa, F. Tomasini, G. Tromba, and A. Vacchi, Nucl. Instru. and Meth. A353 (1994) 366.

[32] R.E. Johnston, D. Washburn, P. Pisano, W.C. Thomlinson, L.D. Chapman, N.F. Gmür, Z. Zhong, and D. Sayers, Medical Imaging 1995: Physics of Medical Imaging, SPIE 2432 (1995) 434.

[33] D. Chapman, W. Thomlinson, F. Arfelli, N. Gmür, Z. Zhong, R. Menk, R.E. Johnston, D. Washburn, E. Pisano, and D. Sayers, Proceedings of the SRI'95 Conference, Oct. 1995, Argonne National Laboratory, Rev. Sci. Instrum., to be published.

[34] E. Rubenstein, E.B. Hughes, L.E. Campbell, R. Hofstadter, R.L. Kirk, T.J. Krolicki, J.P. Stone, S. Wilson, H.D. Zeman, W.R. Brody, A. Macovski, and A.C. Thompson, SPIE 314 (1981) 42.

[35] W. Manning, W. Li, and R. Edelman, N. Engl. J. Med. 328 (1993) 828.

[36] E.N. Dementiev, E. Ya. Dovga, G.N. Kulipanov, A.S. Medvedko, N.A. Mezentsev, V.F. Pindyurin, M.A. Sheromov, N.A. Skrinsky, A.S. Sokolov, V.A. Ushakor, and E.I. Zagorodnikov, Nucl. Instr. Meth. A246 (1987) 726.

[37] E.N. Dementiev, I.P. Dolbnya, E. I. Zagorodnikov, K.A. Kolesnikov, G.N. Kulipanov, G. Kurylo, A.S. Medvedko, N.A. Mezentsev, V.F. Pindyurin, V. Cheskidov, and M.A. Sheromov, Rev. Sci. Instrum. 60 (1989) 2264.

[38] E. Rubenstein, R. Hofstadter, H.D. Zeman, A.C. Thompson, J.N. Otis, G.S. Brown, J.C. Giacomini, H.J. Gordon, R.S. Kernoff, D.C. Harrison, and W. Thomlinson, Proc. Natl. Acad. Sci. USA 83 (1986) 9724.

[39] A.C. Thompson, E. Rubenstein, R.S. Kernoff, H. Zeman, N. Gmür, W. Thomlinson, R. Hofstadter, J.C. Giacomini, H.J. Gordon, and G.S. Brown, SPIE 1140 (1989) 201.

[40] W. Thomlinson, N. Gmür, D. Chapman, R. Garrett, N. Lazarz, J. Morrison, P. Reiser, V. Padmanabhan, L. Ong, S. Green, A. Thompson, H. Zeman, R. Hofstadter, G. Brown, J. Giacomini, H. Gordon, and E. Rubenstein, The Lancet 337 (1991) 360. 
[41] W. Thomlinson, Proceedings of the International School E. Fermi - CXXVII Course Biomedical Applications of Synchrotron Radiation, eds. E. Burattini and A. Balerna (IOS Press, Amsterdam, 1995).

[42] W.-R. Dix, K. Engelke, G. Heintze, H. Heuer, W. Graeff, W. Kupper, M. Lohmann, I. Makin, T. Moechel, R. Reumann, and K.-H. Stellmaschek, SPIE 1090 (1989) 282.

[43] W.-R. Dix, Prog. Biophys. Molec. Biol. 63 (1995) 159.

[44] W.-R. Dix, Synch. Rad. News 8 (1995) 38.

[45] H. Moulin, P. Suortti, and C. Schultze, Physica Medica IX (1993) N2.

[46] A. Akisada, M. Ando, K. Hyodo, S. Hasegawa, K. Konishi, K. Nishimura, A. Maruhashi, F. Toyofuku, A. Suwa, and K. Kohra, Nucl. Instr. Meth. A246 (1987) 713.

[47] K. Umetani, K. Ueda, T. Takeda, M. Akisada, T. Nakajima, and I. Anno, Nucl. Instr. Meth. A301 (1991) 579.

[48] T. Takeda, Y. Itai, J. Wu, S. Ohtsuka, K. Hyodo, M. Ando, K. Nishimura, S. Hasegawa, T. Akatsuka, and M. Akisada, Acad. Radiol. 2 (1995) 602.

[49] S. Ohtsuka, Y. Sugishita, and K. Hyodo, Synch. Rad. News 7 (1994) 21.

[50] H. Mori, K. Hyodo, K. Tobita, M. Chujo, Y. Shimozaki, Y. Sugishita, and M. Ando, Circulation 89 (1994) 865.

[51] T. Takeda, Y. Itai, H. Yoshioka, K. Umetani, K. Veda, and M. Akisada, Med. \& Biol. Eng. \& Comput. 32 (1994) 462.

[52] N. Gmür, D. Chapman, W. Thomlinson, K. Scalia, N. Malloy, J. Mangano, and J. Jacob, Synch. Rad. News 7 (1994) 34.

[53] N. Gmür, D. Chapman, W. Thomlinson, A. Thompson, W. Lavender, K. Scalia, N. Malloy, J. Mangano, and J. Jacob, Rev. Sci. Instrum 66 (1995) 1357.

[54] H.D. Zeman and D.P. Siddons, Nucl. Instr. and Meth. A291 (1990) 67.

[55] E. Rubenstein, J.C. Giacomini, H.J. Gordon, J.A.L. Rubenstein, and G. Brown, Nucl. Instr. and Meth. A364 (1995) 360.

[56] E. Rubenstein, J. Giacomini, H. Gordon, G. Brown, R. O’Neil, W. Thomlinson, D. Chapman, and N. Gmür, Abstract submitted to Biophysics and Synchrotron Radiation Conference, Grenoble, France, Aug. 21-25, 1995.

[57] J.S. Meyer, T. Shinohara, A. Imai, M. Kobari, F. Sakai, T. Hata, W.T. Oravez, G.M. Timpe, T. Deville, and E. Solomon, Neuroradiology 30 (1988) 283.

[58] D.L. Herbert, D. Gur, L. Shabason, W.F. Good, J.E. Rinaldo, J.V. Snyder, H.S. Borovetz, and M.C. Mancici, J. Comput. Assist. Tomogr. 6 (1982) 1088.

[59] M.S. Albert, G.D. Cates, B. Driehuys, W. Happer, B. Saam, C.S. Springer, and A. Wishnia, Nature 370 (1994) 199.

[60] J. Giacomini, Private Communication.

[61] R.G. Fairchild and V.P. Bond, Strahlentherapie 160 (1984) 758.

[62] B. Larsson, Acta. Radiol. Suppl. 365 (1983) 58.

[63] D.N. Slatkin, P. Spanne, F.A. Dilmanian, and M. Sandburg, Med. Phys. 19 (1992) 1398.

[64] D.T. Goodhead, in Synchrotron Radiation in the Biosciences, eds. B. Chance, et al. (Oxford University Press, 1994) 683.

[65] K. Kobayashi, Proceedings of the International School E. Fermi - CXXVIII Course Biomedical Applications of Synchrotron Radiation, eds. E. Burattini and A. Balerna (IOS Press, Amsterdam, 1995).

[66] G. Tisljar-Lentulis and L.E. Feinendegen, Current Topics in Radiation Research Quarterly 12 (1977) 526. 
[67] K. Shinohara, H. Ohara, K. Kobayashi, H. Maesawa, K. Hieda, S. Okada, and T. Ito, J. Radiat. Res. 26 (1985) 334.

[68] D. Larson, W.J. Bodell, C. Ling, T.L. Phillips, M Schell, D. Schrieve, and T. Troxel, Int. J. Radiat. Oncol. Bio. Phys. 16 (1989) 171.

[69] H. Menke, W. Köhnlein, S. Joksch, and A. Halpern, Int. J. Radiat. Biol. 59 (1991) 85.

[70] B.H. Laster, W.C. Thomlinson, J. Kalef-Ezra, V. Benary, E.A. Popenoe, V.P. Bond, C. Gordon, L. Warkentien, N. Gmür, N. Lazarz, and R.G. Fairchild, in Biophysical Aspects of Auger Processes, eds. R.W. Howell, V.R. Narva, K.S.R. Sastry, and D.V. Rao, AAPM Symposium Series 8 (1992) 91.

[71] B.H. Laster, W.C. Thomlinson, and R.G. Fairchild, Radiat. Res. 133 (1993) 219.

[72] R.G. Fairchild, J. Kalef-Ezra, S. Packer, L. Wielopolski, B.L. Laster, J.S. Robertson, L. Mausner, and C. Kannelitsas, Phys. Med. Biol. 32 (1987) 847.

[73] W. Thomlinson, B.H. Laster, G. Shani, L. Warkentien, L.E. Siddons, Z. Zhong, and S.B. Kahl, Abstract submitted to Biophysics and Synchrotron Radiation Conference, Grenoble, France, Aug. 21-25, 1995.

[74] A.-C. Jonsson, B.-A. Jönsson, G. Grafström, S.-E. Strand, and P. Spanne, Abstract submitted to Biophysics and Synchrotron Radiation Conference, Grenoble, France, Aug. 2125, 1995.

[75] B. Larsson, W. Burkard, N. Crompton, C. Nievergelt, C. Schulze, J. Stepanek, and R. Weinreich, Abstract submitted to Biophysics and Synchrotron Radiation Conference, Grenoble, France, Aug. 21-25, 1995.

[76] L. Leksell, J. Neurosurg. Physiat. 46 (1983) 797.

[77] D.N. Slatkin, F.A. Dilmanian, M.M. Nawrocky, P. Spanne, J.-O. Gebbers, D.W. Archer, and J.A. Laissue, Rev. Sci. Instrum. 66 (1995) 1459.

[78] D.N. Slatkin, P. Spanne, F.A. Dilmanian, J.-O. Gebbers, and J.A. Laissue, Proc. Natl. Acad. Sci. USA 92 (1995) 8783.

[79] A.J. Van der Kogel, in Radiation Injury to the Nervous System, eds. P.H. Gutin, S.A. Leibel, and G.E. Sheline (Raven Press, New York) (1991) 91.

[80] P. Spanne, Abstract submitted to Biophysics and Synchrotron Radiation Conference, Grenoble, France, Aug. 21-25, 1995.

[81] R. Andres and B. Larsson, in Hadrontherapy in Oncology, eds. U. Amaldi and B. Larsson (Elsevier, Amsterdam, 1994).

[82] H. Yokomizo, K. Yanagida, S. Sasaki, T. Harami, H. Konishi, K. Masahiko, K. Ashida, S. Harada, H. Hashimoto, M. Iizuka, M. Kabasawa, K. Nakayama, K. Yamada, and Y. Suzuki, Rev. Sci. Instrum. 60 (1989) 1724. 


\section{Table 1}

IMAGING AND THERAPEUTIC MEDICAL TECHNOLOGIES

\begin{tabular}{|l|l|l||}
\hline Radiography & X-Rays & $\begin{array}{l}\text { Angiography } \\
\text { Dental and Surgical X-Rays } \\
\text { Tumor Imaging } \\
\text { Projection Images }\end{array}$ \\
\hline CAT Scans & X-Rays & Anatomical CT Images \\
\hline Nuclear Medicine & Radioisotopes & $\begin{array}{l}\text { CT Images (PETT, SPECT) } \\
\text { Whole Body Counters } \\
\text { Radioisotope Therapy } \\
\text { Coronary Function }\end{array}$ \\
\hline Radiotherapy & $\begin{array}{l}\text { Cancer Radiotherapy } \\
\text { Radiosurgery }\end{array}$ \\
\hline $\begin{array}{l}\text { Magnetic Resonance Imaging } \\
\text { MRD }\end{array}$ & Radio Frequency Magnetic Fields & Anatomical CT Images \\
\hline Ultrasound & Ultrasonic Acoustic Waves & $\begin{array}{l}\text { Anatomical Images } \\
\text { Cardiac Function }\end{array}$ \\
\hline
\end{tabular}

Table 2

APPLICATION OF SYNCHROTRON SOURCES TO MEDICINE

\begin{tabular}{||l|l||}
\hline \multicolumn{1}{|c|}{ Synchrotron Characteristic } & \multicolumn{1}{c|}{ Advantages } \\
\hline High Flux & Monochromatic Beams \\
\hline Continuous Spectrum & Narrow Energy Band Tunable Source \\
\hline Monochromatic Beams & No Beam Hardening \\
\hline Tunable Energy Spectrum & $\begin{array}{l}\text { Dose Effectiveness } \\
\text { Elemental Analysis } \\
\text { K-Edge Image Enhancement } \\
\text { Image/Therapy Optimization }\end{array}$ \\
\hline \multicolumn{1}{|c|}{ Synchrotron Characteristic } & \multicolumn{1}{c|}{ Disadvantages } \\
\hline Planar Beam & 2 Dimensional Image Constraints \\
\hline Large Facilities & Limited Access, High Facility Cost \\
\hline
\end{tabular}


SYNCHROTRON BASED MEDICAL RESEARCH

\begin{tabular}{||l|l|l|l||}
\hline \multicolumn{1}{|c|}{$\begin{array}{c}\text { TYPE OF IMAGE } \\
\text { OR THERAPY }\end{array}$} & \multicolumn{1}{|c|}{$\begin{array}{c}\text { PRIMARY } \\
\text { ANATOMY }\end{array}$} & \multicolumn{1}{|c||}{$\begin{array}{c}\text { RESEARCH } \\
\text { STATUS }\end{array}$} \\
\hline Angiography & Projection Image & Coronary Arteries & Human Studies \\
\hline Computed Tomography & CT Image & Head and Neck & Animal Models \\
\hline Radiotherapy & Microbeam Therapy & Brain Tumors & Animal Models \\
\hline Mammography & Projection Image & Breast Tumors & In-Vitro \\
\hline Bronchography & Projection Image & Lungs & Human Studies \\
\hline $\begin{array}{l}\text { Photon Activation } \\
\text { Therapy }\end{array}$ & $\begin{array}{l}\text { Internal/External } \\
\text { Beam Therapy }\end{array}$ & Brain & In-Vitro \\
\hline X-Ray Microscopy & CT or Projection Image & Cells and Tissues & In-Vitro \\
\hline Micro-Tomography & CT Image & Bone & In-Vitro \\
\hline Structural Biology & Crystallography & Protein Structure & In-Vitro \\
\hline EXAFS & Absorption Spectroscopy & $\begin{array}{l}\text { Local Molecular } \\
\text { Structure }\end{array}$ & In-Vitro \\
\hline \hline
\end{tabular}




\section{FIGURE CAPTIONS}

Fig. 1 The $x$-ray flux from the NSLS superconducting wiggler compared with the flux from a conventional tungsten rotating anode $x$-ray tube.

Fig. 2 Schematic top view of the MECT system showing the fan shaped beam, $200 \mathrm{~mm}$ wide, at the patient position. The patient rotates about a vertical axis in the fixed beam.

Fig. 3 Theoretical monochromatic contrast (solid line) compared with the synchrotron measurements at $18 \mathrm{keV}$ using the image plate detector. The phantom was $15 \mathrm{~mm}$ thick Lucite with additional thicknesses of Lucite ( $\mathrm{x}$ axis). The diamond points represent data for the same phantom taken using a conventional clinical based mammography unit operated at $25 \mathrm{kVp}$.

Fig. 4 Schematic diagram of the imaging hardware installed in SMERF. The patient is translated vertically through the intersection of the two beams. The energies of the beams bracket the $\mathrm{k}$-absorption edge of iodine.

Fig. 5 Schematic diagram of a two-dimensional imaging system being developed at the Photon Factory. Photo courtesy of Dr. S. Ohtsuka.

Fig. 6 Intravenous angiogram taken at HASYLAB in the LAO $60^{\circ} / \mathrm{CC} 7^{0}$ projection following peripheral injection of the contrast agent. The scan was performed 13.8 sec after injection and was gated from the ECG to be in systole. This scan took $0.27 \mathrm{sec}$ to complete. The right coronary artery is clearly seen. Photo courtesy of Dr. W.-R. Dix.

Fig. 7 Intravenous angiogram taken at NSLS in the LAO $30^{\circ}$ projection following injection of the contrast agent into the Superior Vena Cava. The scan was performed $13.2 \mathrm{sec}$ after injection and was not gated. This scan took $1.0 \mathrm{sec}$ to complete. RCA is the right coronary artery, AO is the aorta, PV is a pulmonary vein and LV is the left ventricle. 


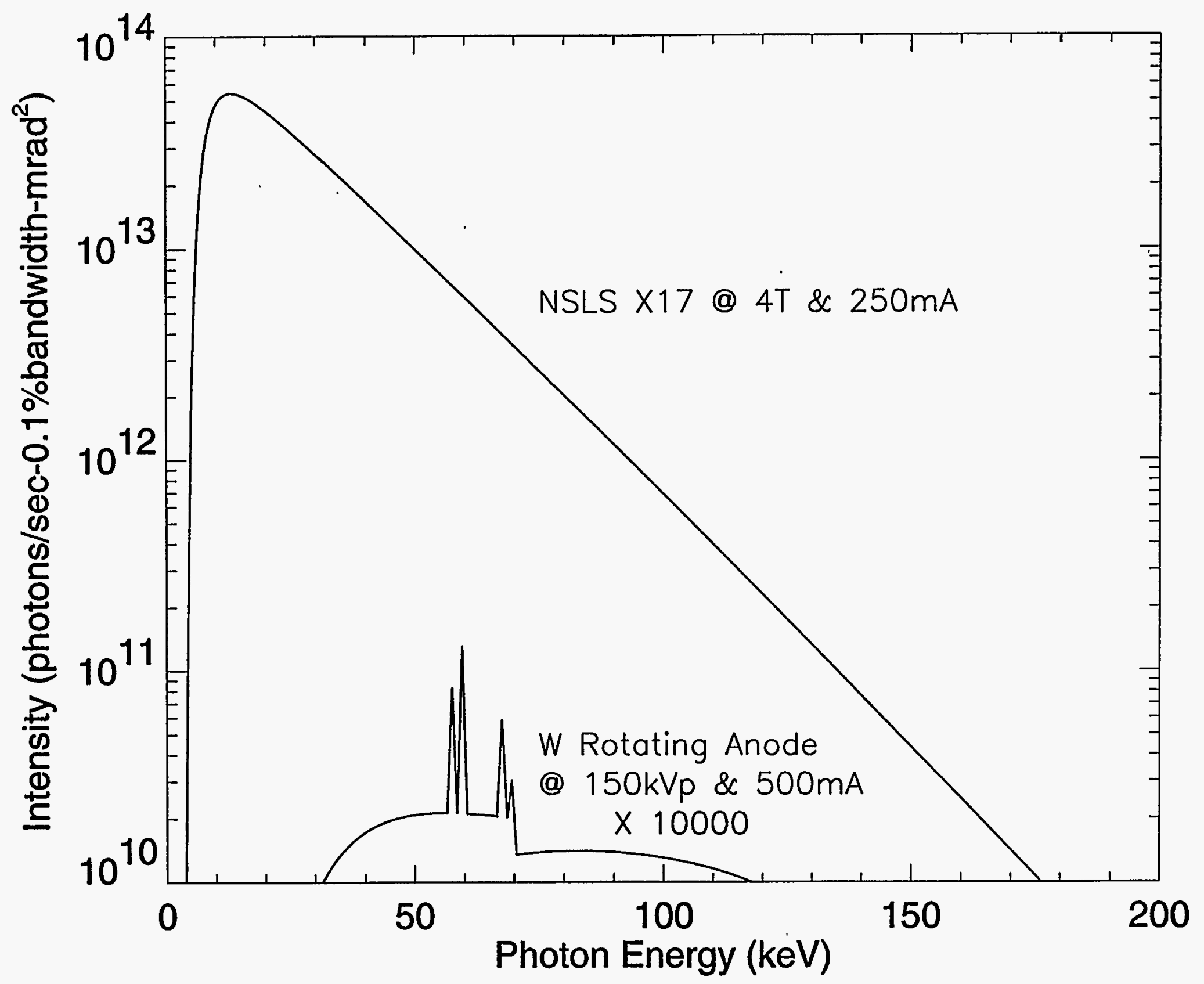

FIG. 1 


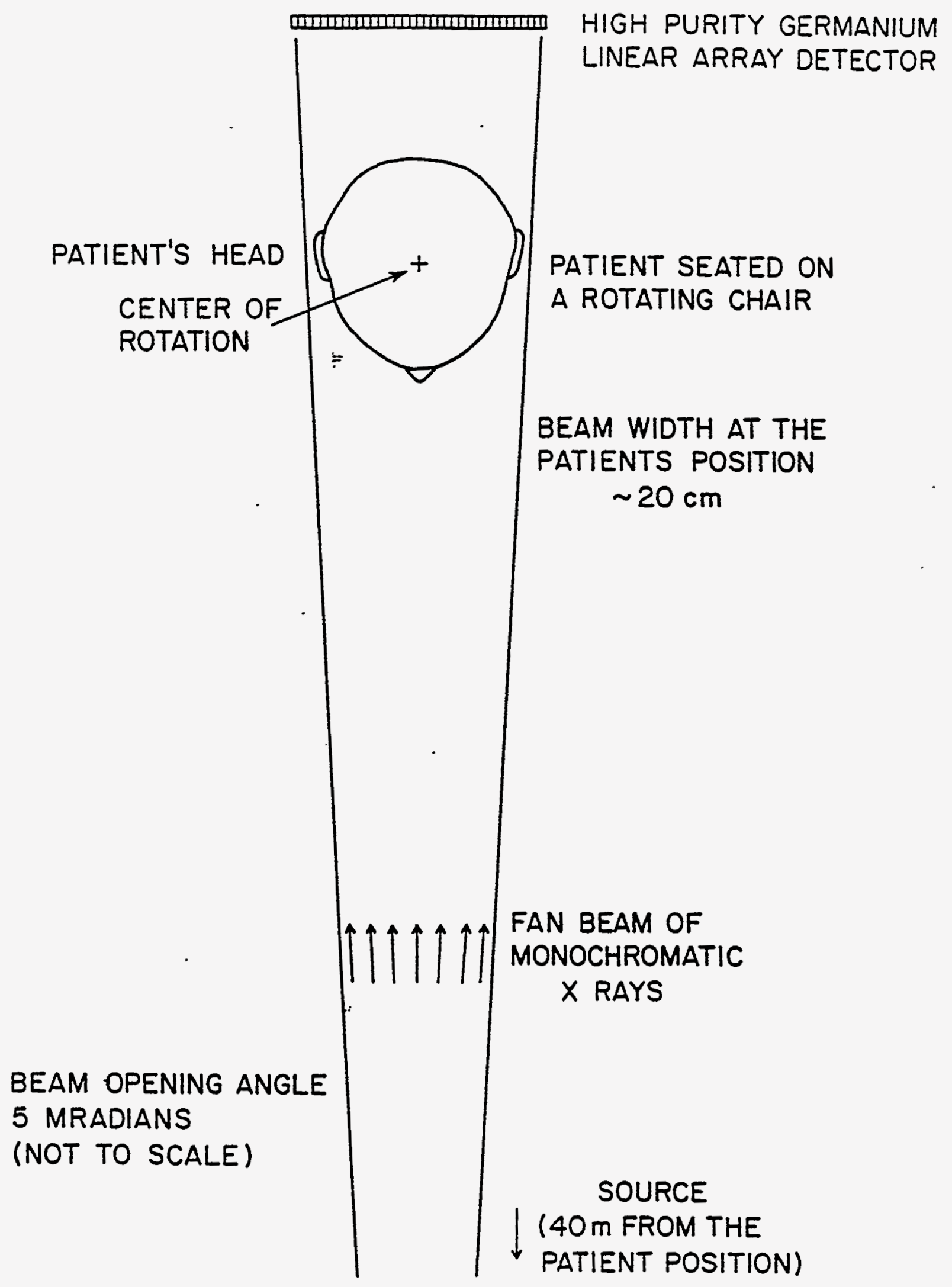

FIG. 2 


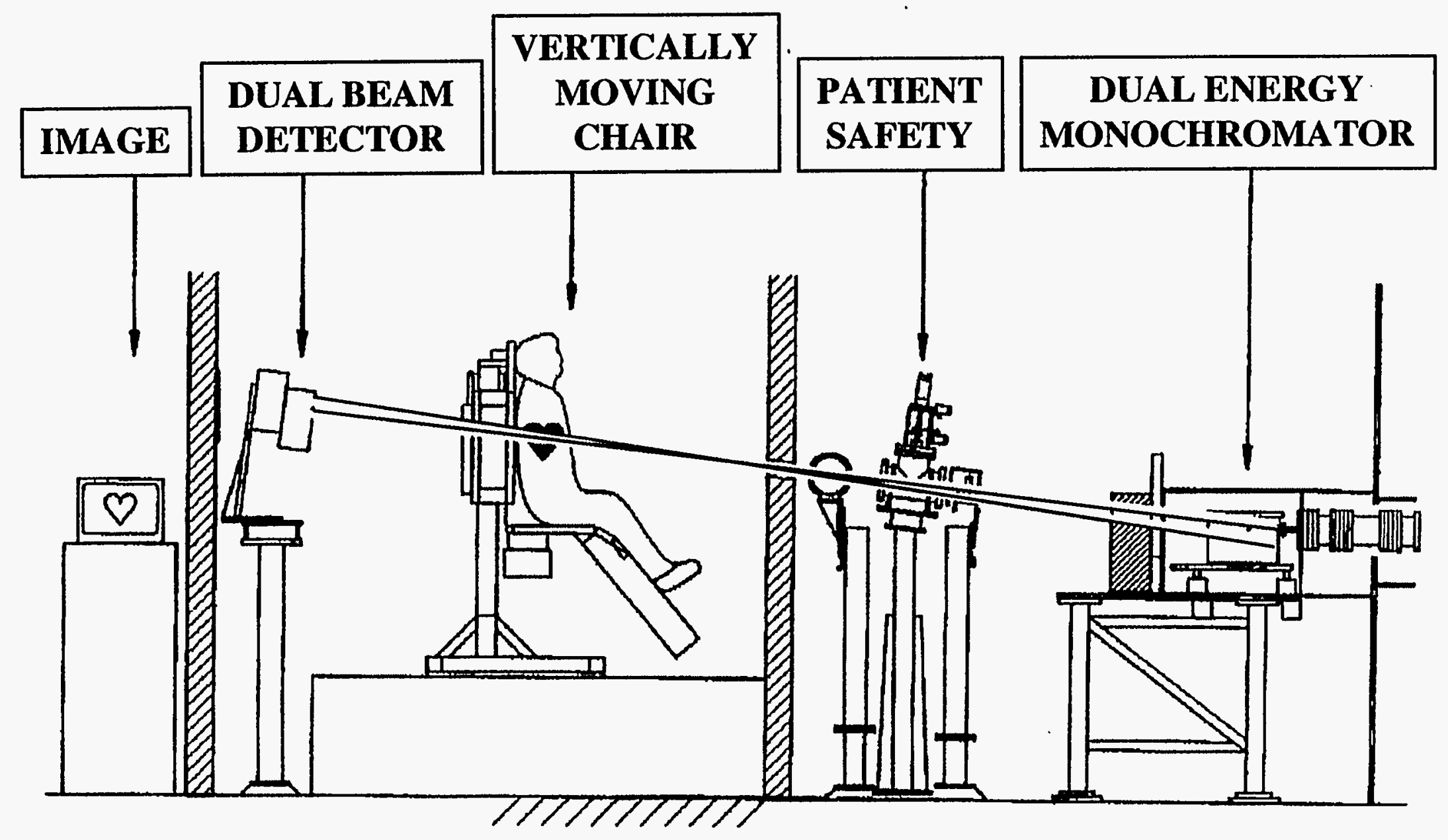

FIG. 4 


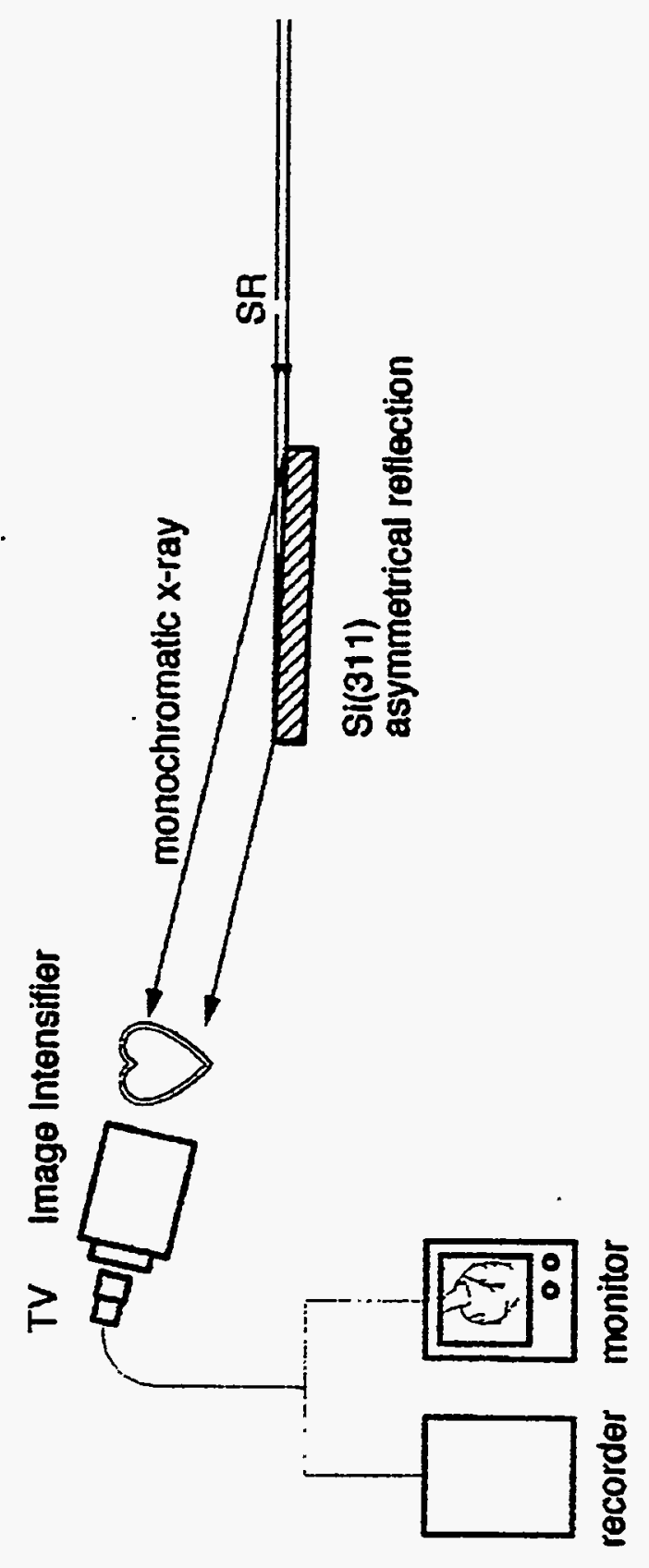




\section{9 'DIH}

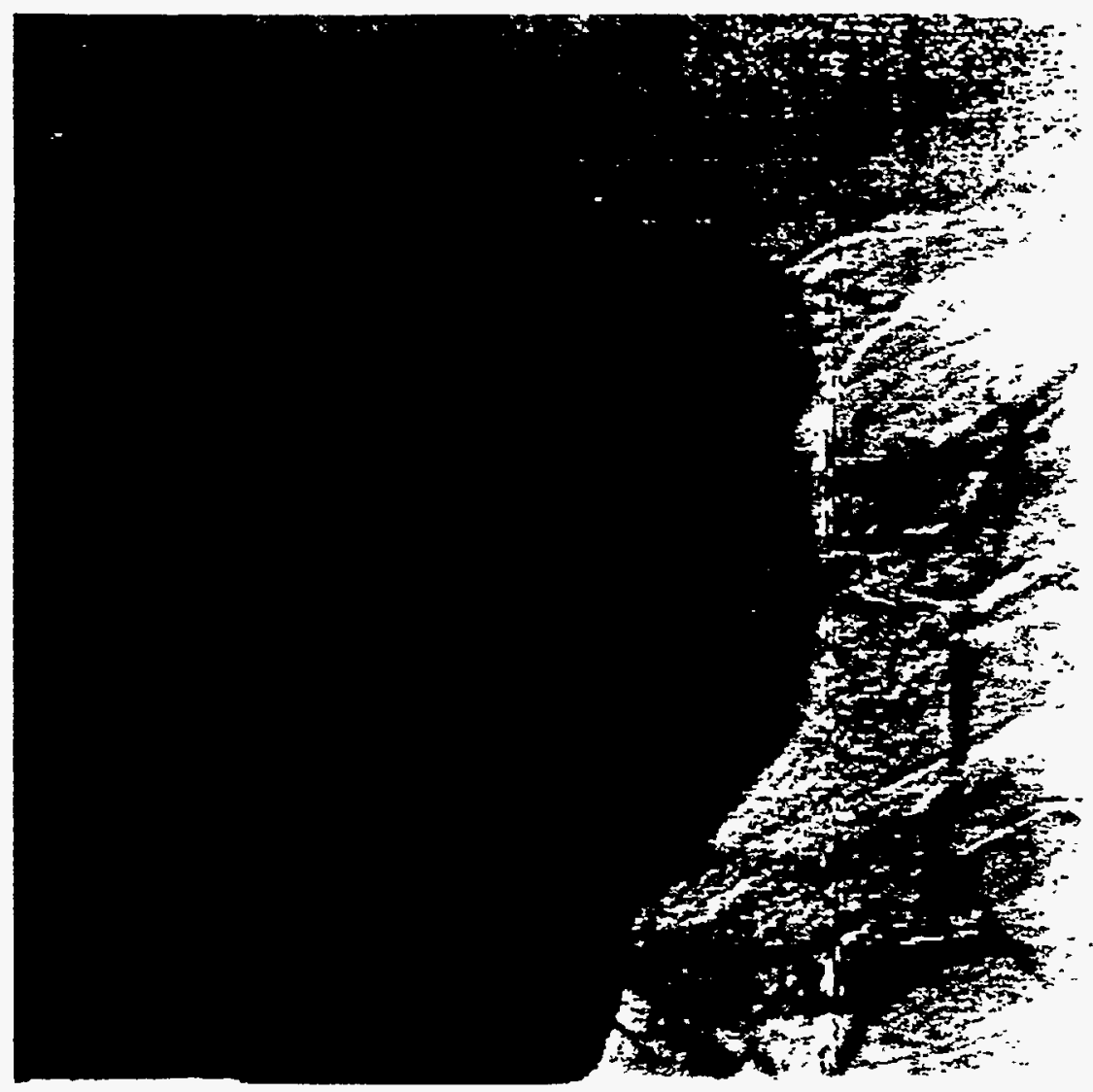


5

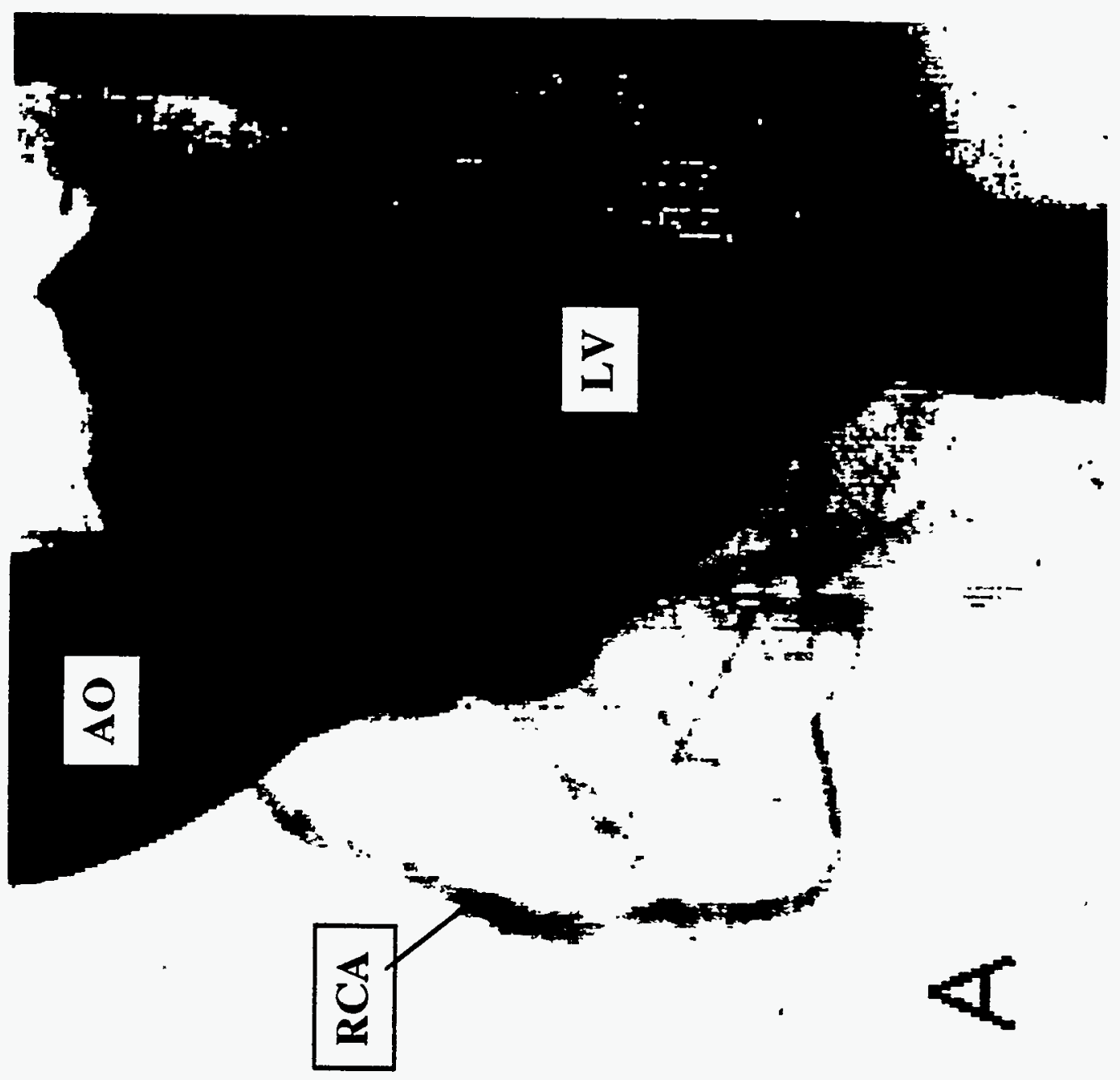


